\title{
Mortality in an antiretroviral therapy programme in Jinja, south-east Uganda: a prospective cohort study
} Barbara Amuron ${ }^{1}$, Jonathan Levin ${ }^{1}$, Josephine Birunghi ${ }^{2}$, Geoffrey Namara ${ }^{1}$, Alex Coutinho ${ }^{3}$, Heiner Grosskurth ${ }^{1,4}$
and Shabbar Jaffar

\begin{abstract}
Background: There have been few reports of long-term survival of HIV-infected patients on antiretroviral therapy (ART) in Africa managed under near normal health service conditions.

Methods: Participants starting ART between February 2005 and December 2006 in The AIDS Support (TASO) clinic in Jinja, Uganda, were enrolled into a cluster-randomised trial of home versus facility-based care and followed up to January 2009. The trial was integrated into normal service delivery with patients managed by TASO staff according to national guidelines. Rates of survival, virological failure, hospital admissions and CD4 count over time were similar between the two arms. Data for the present analysis were analysed using Cox regression analyses.

Results: 1453 subjects were enrolled with baseline median count of 108 cells/Ml. Over time, 119 (8\%) withdrew and 34 (2\%) were lost to follow-up. 197/1453 (14\%) died. Mortality rates (95\% Cl) per 100 person-years were 11.8 $(10.1,13.8)$ deaths in the first year and $2.4(1.8,3.2)$ deaths thereafter. The one, two and three year survival probabilities $(95 \% \mathrm{Cl})$ were $0.89(0.87-0.91), 0.86(0.84-0.88)$ and $0.85(0.83-0.87)$ respectively. Low baseline CD4 count, low body weight, advanced clinical condition (WHO stages III and IV), not being on cotrimoxazole prophylaxis and male gender were associated independently with increased mortality. Tuberculosis, cryptococcal meningitis and diarrhoeal disease were estimated to be major causes of death.
\end{abstract}

Conclusion: Practical and affordable interventions are needed to enable earlier initiation of ART and to reduce mortality risk among those who present late for treatment with advanced disease.

Keywords: Antiretroviral therapy, HIV, Africa, survival, cause of death, adult, Uganda, health care delivery

\section{Background}

Antiretroviral therapy (ART) has been scaled-up rapidly. About 4 million people in Africa are now on ART [1]. Various studies have shown that mortality during the first 6 months or so after initiating ART is much higher than in developed countries and retention of patients in programmes is poor $[2,3]$. However, most longitudinal studies conducted in Africa have been either short-term or have involved small numbers of participants. A recent randomised trial conducted in Uganda and Zimbabwe comparing clinical with laboratory driven monitoring

\footnotetext{
* Correspondence: shabbar.jaffar@lshtm.ac.uk

${ }^{4}$ Faculty of Epidemiology and Population Health, London School of Hygiene and Tropical Medicine, UK

Full list of author information is available at the end of the article
}

found very high and similar 5-year survival rates in the two trials arms of $87 \%$ and $90 \%$ respectively [4]. However, the participants had good access to care and were managed in research clinics by dedicated physicians. Much less is known about long-term survival on antiretroviral therapy under normal health service conditions where access to care is more difficult and the quality and level of clinical support is lower.

Understanding the temporal sequence and causes of death of patients on ART is vital to inform intervention strategies, but most deaths occur at home and cause of death is not determined. There is little understanding of the causes of death of people on ART in Africa. Here we report on the mortality rates of participants followed in an ART programme in a normal health service 
setting in Jinja, SE Uganda, together with the estimated causes of deaths from verbal autopsies.

\section{Methods}

The study was based at The AIDS Support Organisation (TASO) clinic in Jinja, South East Uganda. TASO is a large non-governmental organisation (NGO) which provides care and support to people living with HIV/AIDS. Participants were enrolled in a cluster-randomised trial comparing home-based HIV care with facility care [5]. All adult patients (18 years old or more) living within the TASO catchment population and initiating on ART were invited to join and enrolled consecutively. The trial was integrated into normal health service delivery [5-7]. Trial participants were managed identically to non-trial patients by TASO staff using national guidelines.

Enrolment was done between February 2005 and December 2006 and participants were followed up till $31^{\text {st }}$ January 2009. The trial showed that participants in the home and facility care arms had similar rates of survival, virologic failure, CD4 count recovery, and reported adherence and the costs incurred by the health service were marginally lower in the home-care arm. Just 24/ 1477 (1.6\%) had refused to join the trial. Details of the two arms are published elsewhere [5]. In brief, in the home-based care arm, field officers travelling on motorbikes delivered drugs to the homes of study participants and provided adherence support. Participants were assessed using a checklist and referred to the clinic if necessary. A single repeat home-visit was done for those not found at home, usually 1-2 days after the appointment date. In the facility arm, patients were asked to come monthly to clinic to pick up their drugs. On each visit they were reviewed by a nurse, received adherence counselling and were referred to a physician if necessary. Those who failed to attend clinic were usually visited at home 1-2 days after the appointment date and reminded to attend. Routine clinic visits were scheduled at 2, 6 months after starting ART and 6-monthly thereafter in the home arm and at 2, 3 and 3-monthly thereafter in the facility arm. At each of these visits, participants were reviewed by a counsellor and a physician. Participants in both arms were asked to self-refer at any time they felt unwell. They were declared as lostto-follow-up if their whereabouts were not known on at least 2 occasions one month apart. Routine CD4 count testing was done 6-monthly for all trial participants.

Deaths were detected from TASO records or through home visits. A research physician visited the homes of the deceased, usually more than two months after the death, and collected information on the events, signs and symptoms leading up to the death. Any available medical records were also collected. Two research physicians independently reviewed the information and assigned the probable cause of death. These records were reviewed by a senior independent physician from the government referral hospital to confirm the diagnoses or to resolve discrepancies.

Participants who moved out of the area were withdrawn from the study. Their survival status was ascertained between November 2008 and January 2009 through TASO records and home visits. The trial was approved by the institutional review boards of the Uganda Virus Research Institute, London School of Hygiene and Tropical Medicine, US Center for Disease Control and Prevention and the Uganda National Council of Science and Technology.

\section{Statistical Analysis}

Survival analysis methods were used to analyze the time to death. Subjects who did not die were regarded as being censored on the day that they were last seen or the date of withdrawal or loss to follow-up (unless it was established that a subject who withdrew or was lost to follow-up had later died, in which case they were treated as having died on the date of death recorded during tracing). In order to explore factors associated with mortality, unadjusted mortality rates together with 95\% confidence limits were calculated for each level of the potential exposures and confounders. For the purpose of this descriptive analysis only, continuous covariates were converted to categorical variables.

Factors were considered as risk factors or confounders in models on substantive grounds i.e. on the basis of prior knowledge or biological plausibility [8]. The exposures considered were baseline WHO stage, baseline CD4 count, baseline weight, baseline haemoglobin, whether or not the patient was on cotrimoxazole prophylaxis at baseline, baseline $\log _{10}$ viral load and study arm. Sex and age were regarded as potential confounders of the relationship between risk factors such as CD4 count and mortality. Although the primary analysis of the cluster randomised trial showed no difference in mortality rates between the two study arms, we did investigate study arm as an exposure. In order to evaluate the effect of these explanatory variables, both unadjusted and adjusted Cox proportional hazards regression models were fitted. The models were fitted using robust standard errors to take into account the clustering of subjects in the study design. Since the number of candidate explanatory variables was small, all were included in the final model. Random effects Poisson models were then fitted as a consistency check. Age, weight, CD4 count, haemoglobin and $\log 10$ viral load were treated as continuous covariates and fractional polynomials [9] were used to test for nonlinearity (only CD4 count showed nonlinearity and a first order square root transformation fractional polynomial was found to be 
optimal). Continuous covariates were scaled in order to simplify interpretation of the results. Further Cox regression models were fitted treating CD4 count (again subject to a square root transformation), weight and cotrimoxazole prophylaxis as time varying covariates, to ascertain whether this changed the interpretation compared to the use of the baseline values. All analyses were carried out using Stata release 10.1 (Statacorp. 2007)."

\section{Results}

1453 subjects were enrolled. Table 1 shows the baseline characteristics. The majority (71\%) were women, the median age was 38 years and the median CD4 count was 108 cells/ $\mu$ l. 938 (64.6\%) had a baseline viral load of 100,000 copies/ml or more and 791 (54\%) were at WHO clinical stage III or IV.

119 (8\%) trial subjects withdrew from the trial and 34 (2\%) were lost to follow-up. The reasons for the withdrawals were: 53(4\%) left the area for employment, 25 (2\%) changed to a provider closer to their home, 20(1\%) could no longer afford transport money for clinic visits, $19(1 \%)$ feared disclosure of their HIV status, 1 withdrew after developing side effects to ART and 1 claimed to have been healed spiritually. The median (IQR) time to withdrawal was 350 days $(147$ - 609). The survival status of the participants who withdrew from the trial was as follows: three (3\%) had died, 98 (82\%) were on ART with various other providers, 1 (1\%) was alive and not on ART and 17 (15\%) were no longer in contact with TASO.

Overall, 197/1453 (14\%) trial participants died. During the first year, $154 / 1453$ (11\%) died and the mortality rate was 11.8 deaths $(95 \%$ CI $10.1,13.8)$ per 100 personyears. By 12 months, 1168 subjects were alive and under follow-up. Forty-three (4\%) died after 12 months and the mortality rate was 2.4 deaths $(95 \%$ CI $1.8,3.2)$ per 100 person-years. The one, two and three year survival probabilities $(95 \% \mathrm{CI})$ were $0.89(0.87-0.91), 0.86(0.84$ - 0.88$)$ and $0.85(0.83-0.87)$ respectively (Figure 1$)$. Table 2 shows the mortality rates broken down by the potential explanatory variables. Mortality was higher for males than for females, for those with baseline CD4 cell counts below 50 cells $/ \mu \mathrm{l}$, weight below $50 \mathrm{~kg}$ at baseline, baseline $\mathrm{Hb}$ below $6.5 \mathrm{~g} / \mathrm{dl}$, not on cotrimoxazole prophylaxis and increased with increasing baseline WHO stage. Mortality did not differ between the two study arms.

Table 3 shows the results of fitting unadjusted and adjusted Cox regression models to find factors associated with mortality. Baseline WHO stage, CD4 count,
Table 1 Baseline social and demographic characteristics of the study population

\begin{tabular}{|c|c|}
\hline Number in study & 1453 \\
\hline \multicolumn{2}{|l|}{ Study arm, number (\%) } \\
\hline Facility & $594(41)$ \\
\hline Home & $859(59)$ \\
\hline Women, number (\%) & $1031(71)$ \\
\hline Age in years, median (IQR) & $38(32-44)$ \\
\hline \multicolumn{2}{|l|}{ Education level, number (\%) } \\
\hline No education & $234(16)$ \\
\hline Primary & $816(56)$ \\
\hline Secondary/tertiary & $403(28)$ \\
\hline \multicolumn{2}{|l|}{ Clients' main occupation, number (\%) } \\
\hline Business/self employed/professional & $615(42)$ \\
\hline Farmer & $389(27)$ \\
\hline Unemployed/Housewife & $434(30)$ \\
\hline Other & $15(1)$ \\
\hline \multicolumn{2}{|l|}{ WHO stage, number (\%) } \\
\hline 1 & $20(1)$ \\
\hline$\|$ & $642(44)$ \\
\hline III & $673(46)$ \\
\hline IV & $118(8)$ \\
\hline \multicolumn{2}{|l|}{ CD4 cell count cells/ $\mu$ l at enrolment, number (\%) } \\
\hline$<50$ & $444(30)$ \\
\hline $50-99$ & $232(16)$ \\
\hline $100-200$ & $654(45)$ \\
\hline$>200$ & $123(9)$ \\
\hline Median (IQR) cells/ $\mu \mathrm{l}$ & $108(35-165)$ \\
\hline \multicolumn{2}{|l|}{ Plasma viral load copies/ml, number (\%) } \\
\hline$<1,000$ & $21(2)$ \\
\hline $1,000-9,999$ & $40(3)$ \\
\hline $10,000-99,999$ & $454(31)$ \\
\hline $100,000-999,999$ & $832(57)$ \\
\hline$>=1,000,000$ & 106 \\
\hline Median (IQR), copies/ml & $\begin{array}{c}163,224 \\
(63,616-370,412)\end{array}$ \\
\hline On cotrimoxazole prophylaxis, number (\%) & $1403(97 \%)$ \\
\hline \multicolumn{2}{|l|}{ Haemoglobin $\mathrm{g} / \mathrm{dl}$, number (\%)* } \\
\hline$\geq 11$ & $701(48 \%)$ \\
\hline $9.5-10.9$ & $407(28 \%)$ \\
\hline $8.0-9.4$ & $242(17 \%)$ \\
\hline $6.5-7.9$ & $80(6 \%)$ \\
\hline$<6.5$ & $19(1 \%)$ \\
\hline Median g/dl (IQR) & $10.9($ IQR $9.5-12.3)$ \\
\hline \multicolumn{2}{|l|}{ Weight, kg, number (\%) } \\
\hline$<50$ & $431(30 \%)$ \\
\hline $50-60$ & $698(48 \%)$ \\
\hline$>60$ & $317(22 \%)$ \\
\hline Mean kg (sd) & $54.2(9.2)$ \\
\hline
\end{tabular}

Haemoglobin missing for 4 subjects. Weight missing for 7 subjects. $\mathrm{IQR}=$ inter-quartile range; $s \mathrm{~d}=$ standard deviation 


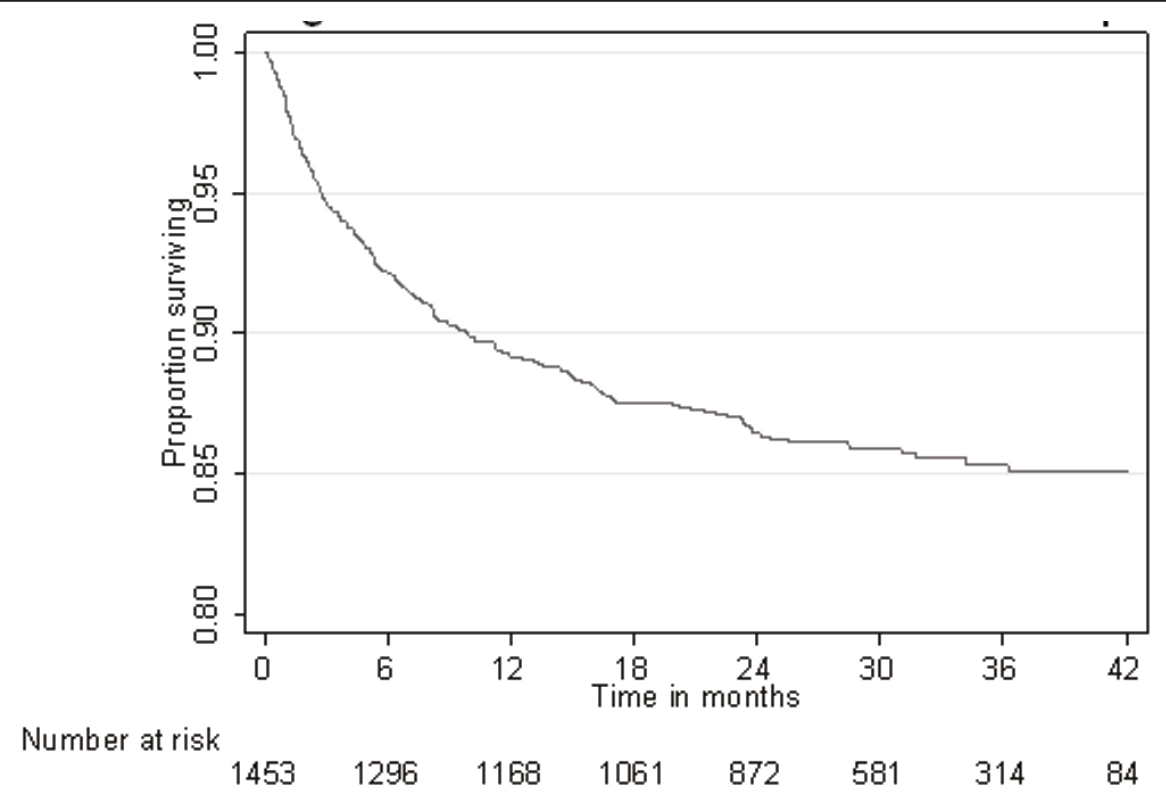

Figure 1 Overall survival over a 42 month duration of follow up in the study

weight, cotrimoxazole prophylaxis and gender were independent predictors of mortality. After adjusting for these factors, baseline viral load, age, $\mathrm{Hb}$ level and study arm were not associated with mortality. Using WHO stage II as a baseline (due to the small number of patients classified as WHO stage I), patients at WHO Stage III and IV were at increased risk. One unit increase in the transformed CD4 count led to a 39\% decrease in risk of death; such a unit increase corresponds to an increase in CD4 count from 0 to 25 , or from 25 to 100 , or from 100 to 225; thus the effect of CD4 count is most pronounced at low CD4 counts. A $5 \mathrm{~kg}$ increase in baseline weight led to a $23 \%$ reduction in the risk of death. The risk of death for patients not on cotrimoxazole prophylaxis was 2.2 times the risk for patients on cotrimoxazole prophylaxis. The risk of death for females was $41 \%$ lower than the risk for males and the risk of death increased by $9 \%$ for every 10 year increase in age at baseline. The proportional hazards assumption in the Cox regression model was tested using the test of Grambsch and Therneu, and there was no evidence against the assumption (global chi-square 15.53 on $11 \mathrm{df}, \mathrm{P}=0.16$ ).

Sensitivity analyses were done to assess the impact of including study arm in the final model and assess the effect of using random effects Poisson models, as was done in the primary analysis of the cluster randomized trial. Including study arm in the model and fitting a random effects Poisson regression had a negligible effect (e. g. the aHR for the effect of a one unit change in the transformed CD4 count changed from 0.61 in the original model to 0.60 when including study arm in the model, while the adjusted rate ratio from the random effects Poisson model was 0.59).

Overall 130/197 deaths occurred among subjects with at most one CD4 count taken at baseline. Overall, 1276 (88\%) subjects had two or more CD4 counts. Of these, 1213 (95\%) had increases in CD4 count and of these, 54 (4\%) died. Sixty-three (5\%) had a drop in CD4 count and 13 (21\%) of these died. Among these 13 deaths, the median drop was 45 cells/ $\mu$ l (IQR 29 - 101) and the decline occurred within the first year in 8 (61.5\%) of these cases. Among the 50/63 who survived, the median drop was 34 cells/ $\mu$ l (IQR 16 - 63) and the decline occurred within the first year in seven cases (14\%). In an adjusted analyses, CD4 count fitted as a time-varying covariate only had a negligible effect (the aHR for a one unit change on the transformed scale was 0.59)

Verbal autopsies suggested that the most common causes of death identified were: CNS infections (n. 25, 13\%), diarrheal disease with dehydration (n. 25, 13\%), tuberculosis (n. $22,11 \%$ ) and acute febrile illness (n. 22, 11\%) (Table 4). Verbal autopsies could not be done for 31 participants: relatives had moved away and could not be traced in 29 cases and there was insufficient information on which to make a diagnosis for 2 cases. There were no striking differences in the estimated causes of deaths between those which occurred within 6-months of ART initiation and which occurred later, although numbers were small.

\section{Discussion}

In this trial, which was integrated into normal health service delivery in Uganda, the mortality rate was almost 
Table 2 Mortality rates by potential baseline risk factors

\begin{tabular}{|c|c|c|c|c|}
\hline Factor & Level & $\mathrm{n}$ & Deaths & Mortality rate per 100 person-years ( $95 \%$ C.I.) \\
\hline \multirow[t]{2}{*}{ Sex } & Male & 422 & 69 & $8.0(6.3 ; 10.2)$ \\
\hline & Female & 1031 & 128 & $5.7(4.8 ; 6.8)$ \\
\hline \multirow[t]{3}{*}{ Age } & $\leq 30$ & 251 & 41 & $8.7(6.4 ; 11.8)$ \\
\hline & 31 to 40 & 670 & 83 & $5.8(4.7 ; 7.2)$ \\
\hline & $>40$ & 532 & 73 & $6.2(4.9 ; 7.7)$ \\
\hline \multirow[t]{4}{*}{ WHO stage } & 1 & 20 & 1 & $2.3(0.3 ; 16.0)$ \\
\hline & $\|$ & 642 & 55 & $3.8(2.9 ; 5.0)$ \\
\hline & III & 673 & 109 & $7.8(6.5 ; 9.4)$ \\
\hline & IV & 118 & 32 & $14.9(10.5 ; 21.0)$ \\
\hline \multirow[t]{5}{*}{ Baseline CD4 count cells $/ \mathrm{mm}^{3}$} & $<50$ & 444 & 110 & $13.0(10.8 ; 15.6)$ \\
\hline & $50-99$ & 232 & 20 & $3.9(2.5 ; 6.0)$ \\
\hline & $100-149$ & 306 & 33 & $4.9(3.5 ; 6.9)$ \\
\hline & $150-199$ & 339 & 21 & $2.8(1.8 ; 4.2)$ \\
\hline & $\geq 200$ & 132 & 13 & $4.5(2.6 ; 7.7)$ \\
\hline \multirow[t]{5}{*}{ Baseline plasma viral load copies/ml } & $<1,000$ & 21 & 3 & $6.7(2.2 ; 20.7)$ \\
\hline & $1,000-9,999$ & 40 & 2 & $2.6(0.6 ; 10.3)$ \\
\hline & $10,000-99,999$ & 454 & 49 & $4.9(3.7 ; 6.5)$ \\
\hline & $100,000-999,999$ & 832 & 130 & $7.4(6.3 ; 8.8)$ \\
\hline & $>1,000,000$ & 106 & 13 & $5.7(3.3 ; 9.9)$ \\
\hline \multirow[t]{3}{*}{ Weight $(\mathrm{kg}) *$} & $<50$ & 431 & 94 & $11.0(9.0 ; 13.4)$ \\
\hline & $50-60$ & 698 & 76 & $5.0(4.0 ; 6.3)$ \\
\hline & $>60$ & 317 & 22 & $3.0(2.0 ; 4.6)$ \\
\hline \multirow[t]{6}{*}{ Haemoglobin $(\mathrm{g} / \mathrm{dl})$} & $\geq 11$ & 701 & 76 & $5.0(4.0 ; 6.3)$ \\
\hline & $9.5-10.9$ & 407 & 64 & $7.4(5.8 ; 9.5)$ \\
\hline & $8.0-9.4$ & 242 & 37 & $7.4(5.3 ; 10.2)$ \\
\hline & $6.5-7.9$ & 80 & 12 & $6.7(3.8 ; 11.7)$ \\
\hline & $<6.5$ & 19 & 6 & $19.2(8.6 ; 42.8)$ \\
\hline & Missing & 4 & 2 & \\
\hline \multirow[t]{2}{*}{ On cotrimoxazole prophylaxis } & Yes & 1403 & 185 & $6.2(5.3 ; 7.1)$ \\
\hline & No & 50 & 12 & $12.0(6.8 ; 21.1)$ \\
\hline \multirow[t]{2}{*}{ Study Arm } & Facility Based & 594 & 80 & $6.5(5.2 ; 8.1)$ \\
\hline & Home Based & 859 & 117 & $6.3(5.2 ; 7.5)$ \\
\hline \multirow[t]{5}{*}{ Time following initiating ART } & 0 - 5 months & 1453 & 112 & $16.5(13.7 ; 19.8)$ \\
\hline & 6 - 11 months & 1296 & 42 & $6.7(5.0 ; 9.1)$ \\
\hline & $12-23$ months & 1168 & 32 & $3.0(2.2 ; 4.3)$ \\
\hline & 24 - 35 months & 872 & 8 & $1.3(0.7 ; 2.6)$ \\
\hline & $\geq 36$ months & 314 & 3 & $2.4(0.8 ; 7.6)$ \\
\hline
\end{tabular}

* Weight was missing for 7 people of whom 5 died.

12 deaths per 100 person-years in the first year following ART initiation, five-fold higher than in subsequent years. Indeed from 12 months onwards, the mortality rate in our cohort was only slightly higher than that reported in developed countries [10]. Other studies have reported between 8 and $26 \%$ of patients dying within the first year of starting ART [2]. The mortality rate in the large DART was lower, with 5-year survival of $87 \%$ and $90 \%$ in the clinically driven monitoring versus laboratory and clinical monitoring arms respectively. However, participants in this study had better access to clinical care. The problem in Africa lies with the very high early mortality. We have previously shown an even higher mortality rate, around 30 deaths per 100 personyears, during the pre-treatment screening period [11] in this population and recent reviews show $32 \%$ loss to follow-up during this pre-treatment period despite eligibility for ART [12], a 20\% loss to follow-up among patients within the first year of antiretroviral therapy [13], among whom mortality is very high [14]. Taken together, these findings suggest that the major problem is early mortality and that mortality after 12 months in 
Table 3 Unadjusted and adjusted Cox regression models for baseline factors associated with time to death

\begin{tabular}{|c|c|c|c|c|}
\hline Factor & Level & Unadjusted HR (95\% c.i.) & Adjusted HR (95\% c.i.) & Adjusted P-value \\
\hline \multirow[t]{2}{*}{ Sex } & Male & 1 (ref. level) & 1 (ref. level) & 0.002 \\
\hline & Female & $0.73(0.52 ; 1.02)$ & $0.59(0.44 ; 0.80)$ & \\
\hline \multirow[t]{2}{*}{ Study Arm } & Facility & 1 (ref. level) & 1 (ref. level) & \\
\hline & Home-based & $1.003(0.77 ; 1.31)$ & $0.92(0.70 ; 1.20)$ & 0.56 \\
\hline Age & Per 10 year increase & $1.002(0.84 ; 1.20)$ & $1.09(0.91 ; 1.31)$ & 0.30 \\
\hline \multirow[t]{4}{*}{ WHO stage } & 1 & $0.58(0.08 ; 4.0)$ & $0.72(0.12 ; 4.42)$ & 0.009 \\
\hline & $\|$ & 1 (ref. level) & 1 (ref. level) & \\
\hline & III & $1.99(1.57 ; 2.53)$ & $1.41(1.09 ; 1.83)$ & \\
\hline & IV & $3.64(2.53 ; 5.23)$ & $2.23(1.45 ; 3.43)$ & \\
\hline$\sqrt{ } \mathrm{CD} 4 / 25$ & Per transformed CD4 increase * & $0.52(0.44 ; 0.61)$ & $0.61(0.51 ; 0.73)$ & $<0.001$ \\
\hline $\log _{10}$ plasma viral load & Per 1 log increase & $1.15(1.004 ; 1.31)$ & $1.04(0.91 ; 1.18)$ & 0.51 \\
\hline Weight & Per $5 \mathrm{~kg}$ increase & $0.74(0.67 ; 0.82)$ & $0.77(0.70 ; 0.85)$ & $<0.001$ \\
\hline Haemoglobin & Per $2 \mathrm{~g} / \mathrm{dl}$ increase & $0.82(0.72 ; 0.93)$ & $0.93(0.81 ; 1.07)$ & 0.35 \\
\hline Cotrimoxazole prophylaxis & $\begin{array}{l}\text { Yes } \\
\text { No }\end{array}$ & $\begin{array}{c}1 \text { (ref. level) } \\
2.03(1.08 ; 3.81)\end{array}$ & $\begin{array}{c}1 \text { (ref. level) } \\
2.18(1.10 ; 4.34)\end{array}$ & 0.02 \\
\hline
\end{tabular}

* Because of the CD4 count transformation, per unit increases here means an increase in CD4 count from 0 to 25, or from 25 to 100 , or from 100 to 225 etc;

well functioning programmes will be low. We believe our findings are robust. Very few individuals refused to join the study, the loss-to-follow-up was low and the mortality rate among subjects who withdrew was similar to those who were retained in care.

Patients in Africa generally present late for HIV treatment with CD4 count typically well below 200 cells per microlitre [15], as was the case in our study. Much of the mortality in our study was attributed to tuberculosis, cryptococcal meningitis and diarrhoea and clearly some of this could have been prevented had patients initiated ART earlier. However earlier ART initiation will not be a reality for many because of the costs and difficulties of accessing care, particularly for chronic conditions such as HIV which require regular contact with health services. We have previously shown that a single visit to the clinic in our area costs $13 \%$ of a man's and $20 \%$ of woman's monthly salary and that the cost of transport is a major factor inhibiting patients starting ART [5]. There is therefore an urgent need to identify practical

Table 4 Causes of death overall and stratifed by when the death occurred after initiation of ART, number (\%)

\begin{tabular}{llcc}
\hline & Overall & Deaths $<\mathbf{6}$ months & Deaths $\geq 6$ months \\
\hline Cause of Death & $25(13)$ & $19(17)$ & $6(7)$ \\
\hline Central nervous system infections & $25(13)$ & $17(15)$ & $8(10)$ \\
\hline Diarrheal disease with dehydration & $22(11)$ & $13(12)$ & $9(11)$ \\
\hline Tuberculosis & $22(11)$ & $14(12)$ & $8(10)$ \\
\hline Acute febrile illness & $14(7)$ & $8(7)$ & $6(7)$ \\
\hline Poor feeding/starvation & $13(7)$ & $5(6)$ & $6(7)$ \\
\hline Anaemia & $13(7)$ & $4(7)$ & $4(5)$ \\
\hline Septicemia & $7(4)$ & $7(6)$ & $3(4)$ \\
\hline Pneumonia & $5(3)$ & $3(3)$ & $2(2)$ \\
\hline Hemorrhage & $4(2)$ & $2(2)$ & $0(0)$ \\
\hline Cardiovascular Disease & $4(2)$ & $2(2)$ & $2(2)$ \\
\hline Kaposi's Sarcoma & $3(2)$ & $4(4)$ & $3(4)$ \\
\hline Trauma/accidents & $3(2)$ & $1(1)$ & $1(1)$ \\
\hline Liver failure & $2(1)$ & $0(0)$ & $2(2)$ \\
\hline Suicide & $4(2)$ & $1(1)$ & $19(23)$ \\
\hline Other & $31(16)$ & $2(2)$ & 84 \\
\hline Unknown & 197 & $12(11)$ & 113 \\
\hline Total & & & \\
\hline
\end{tabular}


interventions which will reduce early mortality among the many patients who will continue to present with advanced HIV associated disease for the foreseeable future.

Our study also identified several factors associated independently with mortality. As expected low baseline CD4 count and WHO clinical stage III or IV were associated independently with increased mortality; but there was no association with plasma viral load. Most patients who died had only one CD4 count measured at baseline. Among those in whom CD4 count was measured more than once, mortality risk was more than 5 -fold higher among patients who had falls in their CD4 count than those in whom CD4 count increased. However, fitting CD4 count as a time-varying covariate did not significantly improve the fit of the model compared to fitting CD4 count at baseline. Although our numbers were small, this accords with the findings of the DART trial [4] which showed limited additional value of CD4 count monitoring over clinical monitoring. More research is needed to assess the costs and benefits of long-term CD4 count monitoring in settings where access to care is limited.

Men presented at a similar WHO stage and CD4 count as women but had significantly higher plasma viral loads. After adjusting for these and the other factors including whether on cotrimoxazole prophylaxis and weight, men had a much higher mortality than women. Why this is so is puzzling. We know that in most settings, fewer men access antiretroviral services $[13,16]$. One explanation for their higher mortality could be that men maintain less contact with health services and have poorer adherence to treatment. This needs further investigation in other cohorts. If true, it points to a poor prognosis for men: fewer start antiretrovirals and those who do may have poorer outcomes.

In conclusion, our study shows that under conditions of normal health services the high early mortality of HIV infected patients starting antiretroviral therapy is associated with low baseline CD4 count, body weight, advanced clinical conditions (WHO stages III and IV), not being on cotrimoxazole prophylaxis and male gender. Practical and affordable interventions are needed to enable earlier initiation of ART and to reduce mortality risk among those who present late for treatment with advanced disease.

\footnotetext{
Acknowledgements

We thank the study patients and TASO staff who made this study happen. Thanks also to Dr Emmanuel Habyara, Ms Sarah Khanakhwa and to Dr Phyllis Awore.

\section{Author details}

${ }^{1}$ MRC/UVRI Uganda Research Unit on AIDS, Entebbe, Uganda. ${ }^{2}$ The AIDS

Support Organisation, Old Mulago Complex, PO Box 10443, Kampala,
}

Uganda. ${ }^{3}$ Infectious Disease Institute, Mulago Hospital Complex, PO Box 22418, Kampala, Uganda. ${ }^{4}$ Faculty of Epidemiology and Population Health, London School of Hygiene and Tropical Medicine, UK.

\section{Authors' contributions}

BA and SJ wrote the first draft of the paper and all authors contributed comments and suggestions to various draft versions. $J$ conducted the statistical analyses and GN managed the data. JB was responsible for patient management and JB, BA, GN were responsible for study implementation. $A C, H G$ and $S J$ generated the research ideas, secured funding and coordinated the research programme All authors have seen and approved the final version.

\section{Competing interests}

The authors declare that they have no competing interests.

Received: 27 May 2011 Accepted: 22 October 2011

Published: 22 October 2011

\section{References}

1. Joint United Nations Programme on HIV/AIDS (UNAIDS) and World Health Organization (WHO): AIDS epidemic update Geneva, Switzerland; 2010.

2. Lawn SD, Harries AD, Anglaret X, Myer L, Wood R: Early mortality among adults accessing antiretroviral treatment programmes in sub-Saharan Africa. AIDS 2008, 22(15):1897-908.

3. Jaffar $\mathrm{S}$, Munderi $\mathrm{P}$, Grosskurth $\mathrm{H}$ : Adherence to antiretroviral therapy in Africa: how high is it really? Trop Med Int Health 2008, 13(9):1096-7.

4. Mugyenyi P, Walker AS, Hakim J, Munderi P, Gibb DM, Kityo C, Reid A, Grosskurth H, Darbyshire JH, Ssali F, Bray D, Katabira E, Babiker AG, Gilks CF, Kabuye G, Nsibambi D, Kasirye R, Zalwango E, Nakazibwe M, Kikaire B, Nassuna G, Massa R, Fadhiru K, Namyalo M, Zalwango A, Generous L, Khauka P, Rutikarayo N, Nakahima W, Mugisha A, Todd J, Levin J, Muyingo S, Ruberantwari A, Kaleebu P, Yirrell D, Ndembi N, Lyagoba F, Hughes P, Aber M, Lara AM, Foster S, Amurwon J, Wakholi BN, Whitworth J, Wangati K, Amuron B, Kajungu D, Nakiyingi J, Omony W, Tumukunde D, Otim T, Kabanda J, Musana H, Akao J, Kyomugisha H, Byamukama A, Sabiiti J, Komugyena J, Wavamunno P, Mukiibi S, Drasiku A, Byaruhanga R, Labeja O, Katundu P, Tugume S, Awio P, Namazzi A, Bakeinyaga GT, Katabira H, Abaine D, Tukamushaba J, Anywar W, Ojiambo W, Angweng E, Murungi S, Haguma W, Atwiine S, Kigozi J, Namale L, Mukose A, Mulindwa G, Atwiine D, Muhwezi A, Nimwesiga E, Barungi G, Takubwa J, Mwebesa D, Kagina G, Mulindwa M, Ahimbisibwe F, Mwesigwa P, Akuma S, Zawedde C, Nyiraguhirwa D, Tumusiime C, Bagaya L, Namara W, Karungi J, Kankunda R, Enzama R, Latif A, Robertson V, Chidziva E, Bulaya-Tembo R, Musoro G, Taziwa F, Chimbetete C, Chakonza L, Mawora A, Muvirimi C, Tinago G, Svovanapasis P, Simango M, Chirema O, Machingura J, Mutsai S, Phiri M, Bafana T, Chirara M, Muchabaiwa L, Muzambi M, Mutowo J, Chivhunga T, Chigwedere E, Pascoe M, Warambwa C, Zengeza E, Mapinge F, Makota S, Jamu A, Ngorima N, Chirairo H, Chitsungo S, Chimanzi J, Maweni C, Warara R, Matongo M, Mudzingwa S, Jangano M, Moyo K, Vere L, Mdege N, Machingura I, Ronald A, Kambungu A, Lutwama F, Mambule I, Nanfuka A, Walusimbi J, Nabankema E, Nalumenya R, Namuli T, Kulume R, Namata I, Nyachwo L, Florence A, Kusiima A, Lubwama E, Nairuba R, Oketta F, Buluma E, Waita R, Ojiambo H, Sadik F, Wanyama J, Nabongo P, Oyugi J, Sematala F, Muganzi A, Twijukye C, Byakwaga H, Ochai R, Muhweezi D, Coutinho A, Etukoit B, Gilks C, Boocock K, Puddephatt C, Grundy C, Bohannon J, Winogron D, Burke A, Babiker A, Wilkes H, Rauchenberger M, Sheehan S, SpencerDrake C, Taylor K, Spyer M, Ferrier A, Naidoo B, Dunn D, Goodall R, Peto L, Nanfuka R, Mufuka-Kapuya C, Pillay D, McCormick A, Weller I, Bahendeka S, Bassett M, Wapakhabulo AC, Gazzard B, Mapuchere C, Mugurungi O, Burke C, Jones S, Newland C, Pearce G, Rahim S, Rooney J, Smith M, Snowden W, Steens JM, Breckenridge A, McLaren A, Hill C, Matenga J, Pozniak A, Serwadda D, Peto T, Palfreeman A, Borok M: Routine versus clinically driven laboratory monitoring of HIV antiretroviral therapy in Africa (DART): a randomised non-inferiority trial. Lancet 2010, 375(9709):123-31.

5. Jaffar S, Amuron B, Foster S, Birungi J, Levin J, Namara G, Nabiryo C, Ndembi N, Kyomuhangi R, Opio A, Bunnell R, Tappero JW, Mermin J, Coutinho A, Grosskurth $\mathrm{H}$ : Rates of virological failure in patients treated in a home-based versus a facility-based HIV-care model in Jinja, 
southeast Uganda: a cluster-randomised equivalence trial. Lancet 2009, 374(9707):2080-9.

6. Jaffar S, Amuron B, Birungi J, Namara G, Nabiryo C, Coutinho A, Grosskurth $\mathrm{H}$ : Integrating research into routine service delivery in an antiretroviral treatment programme: lessons learnt from a cluster randomized trial comparing strategies of HIV care in Jinja, Uganda. Trop Med Int Health 2008, 13(6):795-800.

7. Amuron B, Coutinho A, Grosskurth H, Nabiryo C, Birungi J, Namara G, Levin J, Smith PG, Jaffar S: A cluster-randomised trial to compare homebased with health facility-based antiretroviral treatment in Uganda: study design and baseline findings. Open AIDS J 2007, 1:21-7.

8. Greenland S: Introduction to regression modeling. In Modern Epidemiology. Edited by: GS Rothman KJ, Lash TI. Lippincott, Williams and Wilkins: Baltimore; 2008:

9. Royston $P, A m b l e r ~ G$, Sauerbrei W: The use of fractional polynomials to model continuous risk variables in epidemiology. Int J Epidemiol 1999, 28(5):964-74

10. Braitstein P, Brinkhof MW, Dabis F, Schechter M, Boulle A, Miotti P, Wood R, Laurent C, Sprinz E, Seyler C, Bangsberg DR, Balestre E, Sterne JA, May M, Egger M: Mortality of HIV-1-infected patients in the first year of antiretroviral therapy: comparison between low-income and highincome countries. Lancet 2006, 367(9513):817-24.

11. Amuron B, Namara G, Birungi J, Nabiryo C, Levin J, Grosskurth H, Coutinho A, Jaffar S: Mortality and loss-to-follow-up during the pretreatment period in an antiretroviral therapy programme under normal health service conditions in Uganda. BMC Public Health 2009, 9:290.

12. Rosen S, Fox MP: Retention in HIV care between testing and treatment in sub-Saharan Africa: a systematic review. PLoS Med 2011, 8(7):e1001056.

13. Fox MP, Rosen S: Patient retention in antiretroviral therapy programs up to three years on treatment in sub-Saharan Africa, 2007-2009: systematic review. Trop Med Int Health 2010, 15(Suppl 1):1-15.

14. Brinkhof MW, Boulle A, Weigel R, Messou E, Mathers C, Orrell C, Dabis F, Pascoe M, Egger M: Mortality of HIV-infected patients starting antiretroviral therapy in sub-Saharan Africa: comparison with HIVunrelated mortality. PLoS Med 2009, 6(4):e1000066.

15. Keiser O, Anastos K, Schechter M, Balestre E, Myer L, Boulle A, Bangsberg D, Toure H, Braitstein P, Sprinz E, Nash D, Hosseinipour M, Dabis F, May M, Brinkhof MW, Egger M: Antiretroviral therapy in resource-limited settings 1996 to 2006: patient characteristics, treatment regimens and monitoring in sub-Saharan Africa, Asia and Latin America. Trop Med Int Health 2008, 13(7):870-9.

16. Cornell M, McIntyre J, Myer L: Men and antiretroviral therapy in Africa: our blind spot. Trop Med Int Health 2011.

doi:10.1186/1742-6405-8-39

Cite this article as: Amuron et al: Mortality in an antiretroviral therapy programme in Jinja, south-east Uganda: a prospective cohort study. AIDS Research and Therapy 2011 8:39.

\section{Submit your next manuscript to BioMed Central and take full advantage of:}

- Convenient online submission

- Thorough peer review

- No space constraints or color figure charges

- Immediate publication on acceptance

- Inclusion in PubMed, CAS, Scopus and Google Scholar

- Research which is freely available for redistribution 